\title{
PENDAMPINGAN PADA INDUSTRI MAKANAN
}

\author{
Syaeful Arief \\ UIN Sunan Kalijaga Yogyakarya \\ Prodi Teknik Industri, Fakultas Sains dan Teknologi \\ Email:syaeful.arief87@gmail.com
}

\begin{abstract}
Abstrak
Pengabdian kepada masyarakat merupakan kegiatan yang menjadi salah satu pilar tegaknya Tri Dharma Perguruan Tinggi. Dengan melaksanakan kegiatan ini, institusi pendidikan tinggi secara langsung mendharmakan dirinya memberikan solusi-solusi untuk masyarakat.

Pengabdian kepada masyarakat dilaksanakan dengan program Pendampingan dengan kasus yang disesuaikan dengan kondisi lapangan masing-masing IKM. Lokasi pengabdian adalah sekelompok industri makanan yang berada di seputaran Desa Kecamatan Godean Kabupaten Sleman. Atas saran dan arahan kelompok, sebagai sasaran khusus dipilih Kelompok PKK dengan beragam kondisi dan kemampuan produksi dengan harapan Kelompok tersebut dapat menjadi agent of change bagi kelompok yang lain.

Hasil dari kegiatan pendampingan masyarakat adalah, Kesadaran yang rendah terhadap pentingnya keselamatan kerja, Belum adanya perencanaan produksi yang tersistematis, Proses produksi yang masih menggunakan alat tradisional, Tempat kerja yang tidak higienis dan tidak ergonomis, Luas lantai produksi yang tidak optimal, Utilisasi peraalatan yang rendah, Produktivitas rendah
\end{abstract}

Kata kunci: IKM, industri makanan, Produktifitas.

\begin{abstract}
Community service is an activity that is one of the pillars of upholding the Tri Dharma of Higher Education. By carrying out this activity, the higher education institution directly dedicates itself to providing solutions for the community.

Community service is carried out with the Assistance program with cases adapted to the field conditions of each IKM. The service location is a group of food industries located around the village of Godean District, Sleman Regency. Based on the group's suggestions and directions, PKK groups with various conditions and production capabilities were selected as special targets in the hope that these groups could become agents of change for other groups. The results of community assistance activities are, low awareness of the importance of work safety, absence of systematic production planning, production processes that still use traditional tools, unhygienic and un ergonomic workplaces, non-optimal production floor area, low equipment utilization. , Low productivity
\end{abstract}

Key words: IKM, food industry, productivity. 


\section{PENDAHULUAN}

Salah satu bentuk kegiatan pengabdian masyarakat yang dapat dilakukan oleh Fakultas Sains dan Teknologi di Kecamatan Godean,

Kabupaten Sleman, Jogjakarta. Kecamatan Godean memiliki luas 26,84 km2 dan terdiri dari 7 desa dan 77 dusun. Bagian utara berbatasan dengan Kecamatan Mlati dan Seyegan, bagian timur dengan Kecamatan Mlati dan Gamping, bagian selatan dengan Kecamatan Moyudan dan Kabupaten Bantul, dan bagian barat dengan Moyudan dan Minggir. Berdasarkan hasil proyeksi penduduk 2010, jumlah penduduk Kecamatan Godean tahun 2019 sebesar 72.028 jiwa, terdiri dari 36.163 laki-laki dan 35.865 perempuan. Perbandingan jenis kelamin di Kecamatan Godean adalah 100,83. Dengan luas wilayah 26,84 $\mathrm{KM}^{2}$, maka kepadatan penduduk Kecamatan Godean adalah 2.684 jiwa per $\mathrm{KM}^{2}$. Desa yang relatif padat penduduknya adalah Desa Sidoarum dengan 5.324 jiwa per $\mathrm{KM}^{2}$.

Kegiatan yang telah dilakukan pada pengabdian masyarakat ini adalah pendampingan produksi pengolahan makanan yaitu, abon ikan dan kering kentang untuk meningkatkan nilai ekonomis. Kegiatan ini kemudian dilajutkan dengan pendampingan pelaksanaan pembuatan kemasan yang dapat bersaing dipasaran.

Masalah utama yang dihadapi industri kecil yaitu nilai tambah produknya yang relatif kecil disebabkan. Kedua, sumber daya manusia yang relatif rendah sehingga tingkat kreatifitas dan inovasi produk juga rendah. Ketiga, jaringan pemasaran yang dimiliki terbatas. Keempat, sistem manajemen organisasi belum berjalan dengan baik. Dengan demikian proses pengembangan dan pembinaan indutri kecil dan menengah menjadi keharusan untuk dilakukan jika tidak ingin tertinggal dan tersingkir dari perkembangan ekonomi di era pasar bebas mendatang.

Dengan pelaksanaan kegiatan ini diharapkan Fakultas Sain dan Teknologi UIN Sunan Kalijaga Yogyakarta yang dalam hal ini diwakili oleh prodi Teknik Industri mampu memberikan sumbangsih nyata bagi perkembangan industri kecil khususnya didaerah Yogyakarta. Selain itu dapat turut serta 
mengharumkan nama UIN Sunan Kalijaga Yogyakarta di kalangan masyarakat.

\section{METODE PENELITIAN}

Pengabdian kepada masyarakat dilaksanakan dengan program Pendampingan dengan kasus yang disesuaikan dengan kondisi lapangan masing-masing IKM. Sebagai gambaran rinci pelaksanaan, dapat dijelaskan beberapa hal terkait metodologi sebagi berikut:

\subsection{Lokasi Pengabdian Masyarakat}

Lokasi pengabdian adalah sekelompok industri obat yang berada di seputaran Kecamatan Godean Kabupaten Sleman. Sebagai sasaran khusus dipilih Kelompok PKK dengan beragam kondisi dan kemampuan produksi dengan harapan Kelompok tersebut dapat menjadi agent of change bagi kelompok yang lain.

\subsection{Jenis dan Sumber Data}

Secara umum, data terkumpul dapat dibagi menjadi dua yaitu:

1. Data primer, merupakan data utama yang terkait langsung dengan objek kajian pengabdian masyarakat dan berhubungan langsung dengan pelaksanaan pendampingan. Data primer terdiri atas: data perkembangan usaha, data produk, data proses produksi, data fasilitas produksi, data karyawan.

2.Data sekunder, merupakan data pendukung yang terkait tidak secara langsung terhadap objek kajian. Data sekunder terdiri atas: data kondisi wilayah dampingan dan data kondisi umum perusahaan.

Rincian jenis data dan sumber data diringkas dalam tabel sebagai berikut:

Tabel 2.1 Rincian jenis data dan sumber data

\begin{tabular}{|c|c|c|c|c|}
\hline No & Jenis & Sumber data & $\begin{array}{c}\text { Teknik } \\
\text { Pengumpulan }\end{array}$ & Keterangan \\
\hline 1 & $\begin{array}{l}\text { Data } \\
\text { perkembangan } \\
\text { usaha }\end{array}$ & \begin{tabular}{|l|} 
Ketua \\
Kelomnok atau \\
Manaiemen
\end{tabular} & $\begin{array}{l}\text { Wauxancara dan } \\
\text { studidokcumen }\end{array}$ & $\begin{array}{l}\text { Gambaran perkembangan } \\
\text { usaha. peluang dan } \\
\text { hambatan usaha. }\end{array}$ \\
\hline 2 & Data produk & $\begin{array}{l}\text { Ketua } \\
\text { Kelompak dan } \\
\text { anggota }\end{array}$ & $\begin{array}{l}\text { Wawancara, studi } \\
\text { dolumen } \\
\text { gbservasi }\end{array}$ & $\begin{array}{l}\text { Jenis dan barakteristiks } \\
\text { produk }\end{array}$ \\
\hline 3 & $\begin{array}{ll}\text { Data } & \text { proses } \\
\text { produksif }\end{array}$ & Anggota & $\begin{array}{l}\text { Jawancara dan } \\
\text { obsercasis }\end{array}$ & $\begin{array}{l}\text { Alur utama dan metode } \\
\text { produksi }\end{array}$ \\
\hline 4 & $\begin{array}{l}\text { Data fasilitas } \\
\text { produksi. }\end{array}$ & Ang & $\begin{array}{l}\text { Wlauxancara dan } \\
\text { gbsercasi }\end{array}$ & $\begin{array}{l}\text { Data mesin dan peralatan } \\
\text { yang disunakan }\end{array}$ \\
\hline 5 & Data karxawan & $\begin{array}{l}\text { Ketua } \\
\text { Kelompok dan } \\
\text { anggota } \\
\end{array}$ & Jlawan & $\begin{array}{l}\text { Identitas dan bempetensi } \\
\text { anggota }\end{array}$ \\
\hline 6 & $\begin{array}{ll}\text { Data } & \text { kondisi } \\
\text { wilayah }\end{array}$ & $\begin{array}{l}\text { Ketua } \\
\text { Kelompok dan } \\
\text { Remerintah } \\
\text { Desa }\end{array}$ & $\begin{array}{l}\text { FGD } \\
\text { wawancara }\end{array}$ & $\begin{array}{l}\text { Kondisi umum } \\
\text { industrimakanan } \\
\text { Gentra } \\
\text { Gedean }\end{array}$ \\
\hline 7 & $\begin{array}{l}\text { Data kendisi. } \\
\text { umuman, } \\
\text { perusahaan }\end{array}$ & $\begin{array}{l}\text { Ketua } \\
\text { Kolompoks }\end{array}$ & Wauxancara & $\begin{array}{l}\text { Kondisi umum masing- } \\
\text { masing perusahaan }\end{array}$ \\
\hline
\end{tabular}




\subsection{Tahapan Pendampingan}

Secara umum tahapan pelaksanaan pendampingan dilaksanakan dalam tiga tahapan yaitu:

1. Perencanaan,tahapan perencanaan tertuang dalam Term of Reference

(ToR) yang telah ditetujui, untuk dilaksanakan melalui kegiatan Pengabdian Kepada Masyarakat dengan mekanisme Pendampingan . Dalam dokumen tersebut tertuang latar belakang, tujuan dan rumusan kegiatan, keterlibatan stakeholder termasuk mahasiswa, rencana pelaksanaan, dan kebutuhan anggaran.

2. Persiapan dilakukan beberapa hal diantaranya:

a. Pendekatan terhadap objek pengabdian Dibantu oleh pemerintah desa dilakukan sosialisasi pelaksanaan program terhadap IKMIKM yang dianggap dapat menjadi agent of change wilayah pendampingan.

b. Penggalangan tim, yang terdiri atas Dosen dan mahasiswa, sebanyak 4 orang Dosen dan 3 orang mahasiswa. Para mahasiswa diberikan materimateri pendampingan dan mengadakan diskusi internal tetang berbagai hal yang terkait dengan pendampingan serta permasalahan yang mungkin terjadi dalam pelaksanaan program berikut usulan rumusan solusinya.

c. Observasi Lapangan dilakukangan dengan terlebih dahulu melakukan Focus Group Discussion (FGD) untuk menjaring berbagai informasi penting terkait keberhasilan pelaksanaan program dan hambatanhambatan yang mungkin terjadi. Hasil FGD kemudian menjadi bahan masukan dalam melaksanaan observasi lapangan untuk memperoleh data-data yang lebih rinci.

d. Perumusan Solusi, berdasarkan hasil observasi lapangan disertai dengan data-data pendukung lainnya dilakukan diskusi internal di kampus UIN Sunan Kalijaga Yogyakarta untuk dilakukan perumusan berbagai alternatif solusi bagi pelaksanaan pendampingan.

e. Pelaksanaan pendampingan dilakukan dalam kurun waktu sekitar satu bulan penuh, berdasarkan rumusan solusi yang disesuaikan dengan kondisi riil lapangan. 
f. Evaluasi dilakukan evaluasi tentang kondisi pelaksanaan program sebagai masukan terhadap masing-masing perusahaan. Selain itu dilakukan evaluasi terhadap efektivitas pelaksanaan program dari sisi akademis, sebagai langkah perbaikan dan pembelajaran bagi pelaksanaan program pengabdian masyarakat selanjutnya.

\section{HASIL DAN PEMBAHASAN}

3.1 Diagnosis potensi lokasi dan kebutuhan masyarakat

Secara administratif Kecamatan Godean, Kabupaten Sleman, Propinsi

Daerah Istimewa Yogyakarta memiliki batas-batas dengan wilayah sebagai berikut :

Sebelah Utara : Kecamatan Mlati Sebelah Timur: Kecamatan Mlati dan Kecamatan Gamping Sebelah Selatan: Kecamatan Moyudan dan Kecamatan Gamping Sebelah Barat: Kecamatan Moyudan dan Minggir

Kecamatan Godean terdiri dari 7 desa yaitu Desa Sidorejo, Sidoluhur, Sidomulyo, Sidoagung, Sidokarto,
Sidoarum, Sidomoyo dan 77 padukuhan. Berdasarkan hasil proyeksi penduduk 2010, jumlah penduduk Kecamatan Godean tahun 2017 sebesar 72.028 jiwa, terdiri dari 36.163 laki-laki dan 35.865 perempuan. Perbandingan jenis kelamin di Kecamatan Godean adalah 100,83. Dengan luas wilayah 26,84 km2, maka kepadatan penduduk Kecamatan Godean adalah 2.684 jiwa per $\mathrm{km} 2$. Desa yang relatif padat penduduknya adalah Desa Sidoarum dengan 5.324 jiwa per km2 . Menurut data registrasi penduduk, jumlah Kepala Keluarga di Kecamatan Godeaan adalah 23.200, dengan rata-rata jiwa per Kepala Keluarga adalah 3 jiwa.

Pasangan usia subur (PUS) yang merupakan salah satu sasaran program KB pada tahun 2017 Di Kecamatan Godean tercatat sebanyak 9313 pasangan Mereka tersebar pada 7 desa dengan jumlah terbesar di desa Sidoarum sebanyak 2395 pasangan ( 25\%) Jumlah peserta KB aktif di Kecamatan Godean tahun 2017 sebanyak 7052 pasangan Proporsi terbesar mereka memilih alat KB suntik yakni sebanyak 3573 orang (51\%) sedangkan alat $\mathrm{KB}$ yang relative sedikit 
penggunanya adalah MOP Kecamatan Godean memiliki sekolah dasar sebanyak 33 terdiri dari 20 sekolah negeri dan 13 swasta, SMP sebanyak 8 terdiri dari 3 sekolah negeri dan 5 swasta, SMA/SMK sebanyak 4, yang semuanya terdiri dari 4 sekolah negeri Fasilitas kesehatan di Kecamatan Godean sebanyak 177 terdiri dari 13 apotik, 105 pos yandu, dan 59 tenaga kesehatan yang terdiri dari 29 dokter, 11 dokter gigi, 17 bidan ,2 orang bong supit

Pertanian adalah kegiatan usaha yang meliputi budi daya tanaman pangan dan hortikultura, perkebunan, perikanan, kehutanan, dan peternakan Luas lahan di Kecamatan Godean adalah $2684 \mathrm{Ha}$, paling banyak dimanfaatkan untuk tanah sawah sebesar $1176 \mathrm{Ha}$ ( 43\%) Untuk tanaman palawija, dilihat dari segi produksinya didominasi oleh tanaman jagung 51,6 ton Tanaman hortikultura untuk sayuran didominasi oleh tanaman cabai merah 1811 kuintal Populasi ternak pada tahun 2017 terdiri dari sapi potong \pm 2156 ekor, domba \pm 5 477 ekor, kuda \pm 45 ekor, kerbau \pm 73 ekor, babi \pm 3394 ekor, kambing \pm 933 ekor Adapun jenis unggas yang diternakkan didominasi oleh ayam buras dengan populasi \pm 17039 ekor. Provinsi D I Yogyakarta merupakan salah satu daerah tujuan wisata Di Kecamatan Godean tidak memiliki tempat wisata alam Akan tetapi yang ada adalah tempat wisata kuliner, yaitu keripik belut Banyak dijumpai pedagang keripik belut di Godean Untuk industri yang banyak dijumpai di Kecamatan Godean adalah industri genteng Banyak dijumpai pengrajin genteng di wilayah Sidoluhur, Sidorejo, dan Sidoagung.

\subsection{PELAKSANAAN}

\section{PENDAMPINGAN}

1. Pendampingan produksi

a) TahapPersiapan,sebelum melakukan pelatihan, dikonsultasikan dengan dosen pendamping secara intensif. Kemudian melakukan observasi terhadap masyarakat sasaran dan melakukan koordinasi kepada pihak yang bersangkutan.

Alat yang digunakan:

1. Parut

2. Baskom 
3.Panci

4.Wajan

5.Susruk

6.Sendok

7.Plastik

8.Timbangan

b) Tahap Pelaksanaan

a. Produksi Abom Ikan Lele

Bahan yang digunakan (1 Resep) :

- 4 kg Ikan Lele

- 100 gram Gula Merah, serut halus

- 4 Butir Kelapa dijadikan santan

- 20 butir Bawang Merah

- 12 siung Bawang Putih

- 2 sdm Ketumbar

- 100 gram Cabai Merah

- 6 lembar daun salam

- Garam secukupnya

- minyak goreng untuk menggoreng

Cara Kerja

1. Bersihkan ikan lele sampai benarbenar bersih

2. Rebus ikan lele hingga matang $( \pm 1$ jam )

3. Pisahkan daging ikan lele dengan durinya, kemudian hancurkan atau lumatkan daging ikan lele sampai halus
4. Haluskan bawang merah, bawang putih, ketumbar dan cabai merah hingga benar-benar lembut

5. Goreng bumbu yang telah dihaluskan sampai harum, kemudian tuangkan santannya aduk terus dampai mendidih

6. Tuangkan daging lele yang telah dicabik-cabik

7. Aduk terus sampai matang dan kering
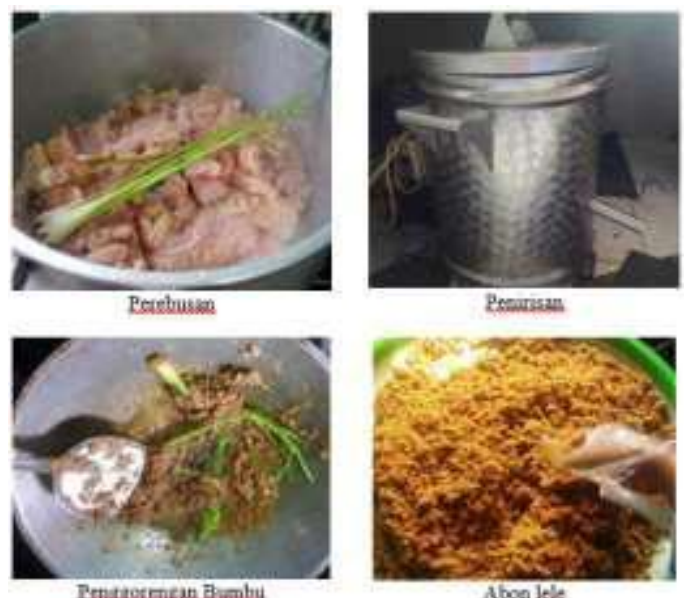

Gambar: Proses Produksi Abon Lele

b. Produksi Kering Kentang Bahan yang digunakan (1 Resep):

- $1 \mathrm{~kg}$ kentang

- 6 siung bawang putih

- 8 butir bawang merah

- 75 gram gula merah

- 2 lembar daun jeruk

- 7 cabai keriting 
- garam dan lada

- minyak goreng

Cara kerja:

1. Kupas kentang dan cuci bersih.

2. Iris tipis-tipis dan goreng sampai kering.

3. Goreng bawang merah, bawang putih, dan cabai sampai harum.

4. Ulek halus bumbu yang sudah digoreng.

5. Tambahkan gula merah, garam, dan daun jeruk.

6. Panaskan wajan dan tumis bumbu halus sampai harum.

7. Masukkan kentang goreng dan aduk terus sampai bumbu merata.

8. Matikan kompor.

9. Angkat dan dinginkan.

\section{Pelatihan kemasan}

Fungsi paling mendasar dari kemasan adalah untuk mewadahi dan melindungi produk dari kerusakan-kerusakan, sehingga lebih mudah disimpan, diangkut dan dipasarkan. Selain itu kemasan juga berfungsi sebagai identitas produk, menambah daya tarik bagi pemberli, sarana promosi bagi konsumen, alat informasi dan komunikasi bagi konsumen. Disamping fungsi utama melindungsi produk, terdapat fungsi lain yang tidak kalah penting, yaitu kemasan sebagai sarana promosi yang berdaya jual dan meningkatkan daya saing produk.

Produk-produk abon dan kering kentang kemasan saat ini banyak yang kurang memperhatikan kemasan sebagai salah satu hal yang penting dalam menentukan minat beli bagi konsumen, namun yang terjadi sekarang banyak bermunculan produk-produk IKM, namun kurang memperhartikan masalah kemasan. Banyak IKM yang kurang memahami selera konsumen. Padahal selera konsumen sangat menentukan keputusan membeli suatu produk. Dilihat dari fungsi dan peran kemasan, perkembangan teknologi kemasan yang kian maju, serta keberadaan kemasan IKM saat ini, maka IKM harus didorong untuk membuat produk yang diterima pasar dengan didukung oleh kemasan yang memenuhi syarat-syarat kemasan yang baik, dan dengan desain dan penampilan yang menarik, unik sehingga mampu bersaing dan menarik minat

3. Pelatihan pemasaran 
Untuk meningkatkan jangkauan pasar serta penguasaan teknologi informasi bagi pelaku usaha UKM yang baru memulai usahanya maka Tim pengabdian masyarakat UIN Sunan

Kalijaga Yogyakarta bekerjasama dengan kelompok tani mengadakan Pelatihan Pemasaran Produk hasil olahan kelompok IKM Melalui Internet. Pelatihan ini diikuti oleh 15 peserta yang berasal dari Kelompok Tani dan hampir semuanya bergerak dalam usaha snack dan makanan.

Pelatihan tersebut mengajarkan para peserta Kelompok Tani tentang

a. Cara membuat email, mengirim email, dan membuka email menggunakan email yahoo

b. Membuat blog menggunakan fasilitas gratis dari weebly.com

c. Cara mengiklankan produk di tokobagus, Kaskus, Instagram,

Facebook dll

Peserta pelatihan UKM ini kebanyakan berasal dari kelompok ibu-ibu yang aktif membantu suami dalam meningkatkan taraf ekonomi keluarga mereka. Walaupun kebanyakan dari mereka banyak yang belum pernah mengenal internet tetapi dengan semangat yang menyala-nyala sedikit demi sedikit akhirnya mereka dapat mempraktekkan apa yang telah diajarkan tutor, tentu saja masih diperlukan pelatihan lanjutan untuk meningkatkan pengetahuan mereka seperti cara membuat label untuk kemasan, cara mengolah foto produk supaya terlihat menarik dan sebagainya.

\section{KESIMPULAN}

Berikut ini adalah kesimpulan dari kegiatan pendampingan masyarakat di desa Kecamatan Godean, Kabupaten Sleman Provinsi Daerah Istimewa Yogyakarta:

Permasalahan yang dihadapi IKM antara lain sebagai berikut:

a. Kesadaran yang rendah terhdap pentingnya keselamatan kerja

b. Belum adanya perencanaan produksi yang tersistematis

c. Proses produksi yang masih menggunakan alat tradisional

d. Tempat kerja yang kotor dan tidak ergonomis

e. Luas lantai produksi yang tidak optimal

f. Utilisasi peraalatan yang rendah

g. Produktivitas rendah 


\section{SARAN}

Kegiatan ini baru menjawab lingkup kecil dari permasalahan yang ada. Diperlukan adanya sinergi antara Pemerintah, Universitas dan Industri dalam memecahkan permasalahan. Kegiatan pendampingan ini merupakan awalan Fakultas Sains dan Teknologi khususnya Jurusan Teknik Industri. Diharapkan kegiatan ini dapat berlanjut dengan pengaturan mekanisme kerjasama yang lain, seperti magang, tugas akhir, dan pengabdian masyarakat.

\section{UCAPAN TERIMA KASIH}

Kami ucapkan terimakasih atas terselenggaranya kegiatan pengabdian kepada masyarakat. Kegiatan ini terselenggara berkat bantuan peningkatan mutu pengabdian kepada masyarakat, UIN Sunan Kalijaga Yogyakarta 